\title{
Modification of prostaglandin F-2 $\alpha$ synthesis and release in the ewe during the initial establishment of pregnancy*
}

\author{
L. Zarco $\uparrow$, G. H. Stabenfeldt $\uparrow$, S. Basu§, G. E. Bradford $\ddagger$ and H. Kindahl§ \\ Departments of $\nmid$ Reproduction and $\ddagger$ Animal Science, University of California, Davis, CA 95616, \\ U.S.A. and §Department of Obstetrics and Gynaecology, College of Veterinary Medicine, \\ Swedish University of Agricultural Sciences, S-750 07 Uppsala, Sweden
}

\begin{abstract}
Summary. Pregnant $(\mathrm{N}=10)$ and non-pregnant $(\mathrm{N}=10)$ ewes were bled every $2 \mathrm{~h}$ from Days 12 to 17 after oestrus (oestrus = Day 0). Plasma concentrations of progesterone, 15-keto-13,14-dihydro-PGF-2 $\alpha$ and 11-ketotetranor-PGF metabolites were determined in all samples. The number of PGF-2 $\alpha$ pulses in non-pregnant ewes was $8.2 \pm 0.4$ (mean \pm s.e.m.) with an interpulse interval of $10.7 \pm 0.7 \mathrm{~h}$. Two or 3 pulses of low frequency (interpulse interval $=13.4 \pm 1.6 \mathrm{~h}$ ) occurred in most non-pregnant ewes before the onset of luteolysis; the interpulse interval then decreased to $7.9 \pm 0.4 \mathrm{~h}$ for the $6 \cdot 0 \pm 0 \cdot 3$ pulses temporally associated with luteolysis. In contrast, the number of PGF- $2 \alpha$ pulses in pregnant ewes was lower $(2.5 \pm 0 \cdot 7,0-8)$ and the interpulse intervals longer $(18.9 \pm 6 \cdot 1 \mathrm{~h})$. Most pulses occurred on Days 14 and 15 in the pregnant and non-pregnant ewes.

The mean concentrations of both PGF- $2 \alpha$ metabolites in non-pregnant ewes were highest on Day 15 while basal levels of both metabolites remained constant at all times. In pregnant ewes, the mean concentrations of both metabolites were highest on Day 14; basal concentrations of both metabolites were also highest on Day 14. The mean concentrations of 15-keto-13,14-dihydro-PGF-2 $\alpha$ were higher in pregnant than in nonpregnant ewes on Days 13 and $14(P<0.05)$ and higher in non-pregnant than pregnant ewes on Day $15(P<0.05)$. The basal concentrations of the 15 -keto metabolite were higher in pregnant than non-pregnant ewes at Days 13,14,15, 16 and $17(P<0.05)$. Both the mean and the basal concentrations of 11-ketotetranor-PGF metabolites were higher in pregnant than in non-pregnant ewes on Day $14(P<0.05)$.

It is concluded that uterine production of PGF-2 $\alpha$ peaks at Days 14-15 after oestrus in pregnant and non-pregnant ewes. Patterns of release differ, however, in that non-pregnant ewes have a pulsatile PGF- $2 \alpha$ pattern superimposed on a constant baseline, while pregnant ewes have an increasing basal secretory pattern which is more nearly continuous, i.e. not pulsatile in form. Modification of pulsatile PGF- $2 \alpha$ synthesis and release is therefore a key aspect of prolongation of luteal function at the beginning of pregnancy in the ewe.
\end{abstract}

Keywords: PGF-2 $\alpha$; sheep; pregnancy

\section{Introduction}

The mechanism by which the embryo prevents regression of the corpus luteum $(\mathrm{CL})$ in the pregnant ewe is not known. Several authors have reported that the pulsatile pattern of prostaglandin (PG)

\footnotetext{
${ }^{*}$ Reprint requests to G. H. Stabenfeldt.

Present address: Department of Reproduction, School of Veterinary Medicine, National Autonomous University of Mexico, Mexico D.F. 04510, Mexico.
} 
F-2 $\alpha$ release observed during luteolysis (Days $12-16$ after oestrus) is not present in pregnant animals, and have concluded that suppression of PGF- $2 \alpha$ release at the critical time for maternal recognition of pregnancy is the mechanism by which the embryo prevents luteolysis (Thorburn et al., 1972, 1973; Barcikowski et al., 1974; Roberts et al., 1975; Peterson et al., 1976; McCracken, 1980; McCracken et al., 1984; Hooper et al., 1986). This view has, however, been challenged by others who have found that the daily mean concentrations of PGF-2 $\alpha$ during the critical period are either similar in pregnant and non-pregnant ewes (Pexton et al., 1975a, b; Nett et al., 1976; Lewis et al., 1977, 1978; Silvia et al., 1984), or higher in pregnant than in non-pregnant animals (Wilson $e t$ al., 1972; Ellinwood et al., 1979).

It has been reported in the goat that the pulsatile release of PGF-2 $\alpha$ which occurs in conjunction with luteolysis in non-pregnant animals is not observed in pregnant animals, but basal secretion of PGF-2 $\alpha$ is higher in pregnant than in non-pregnant goats (Fredriksson et al., 1984). This results in similar mean concentrations of PGF-2 $\alpha$ in pregnant and non-pregnant animals in spite of the different patterns of secretion. If a similar phenomenon occurs in the ewe, it could explain the apparent disagreement between the reports of the absence of PGF- $2 \alpha$ pulses in pregnant ewes and the reports of mean concentrations of PGF- $2 \alpha$ being similar in pregnant and non-pregnant ewes. Available data do not allow either the confirmation or rejection of this possibility since none of the above mentioned studies in the ewe was designed to study simultaneously the pulsatility of PGF- $2 \alpha$ release, the mean concentrations of PGF- $2 \alpha$ or its metabolites, and the basal release of PGF- $2 \alpha$.

The present study was designed to understand the mode of PGF-2 $\alpha$ secretion at the time of initial prolongation of luteal function in the pregnant ewe. We therefore used a sampling schedule adequate to assess pulsatile release of PGF-2 $\alpha$ through the study of the 15-keto-13,14dihydro-PGF-2 $\alpha$ and 11-ketotetranor-PGF metabolites, statistical identification of pulses of PGF- $2 \alpha$ release, quantification of the pulses and their frequency, and calculation of daily mean concentrations and daily basal concentrations of each metabolite in pregnant and non-pregnant ewes.

\section{Materials and Methods}

\section{Animals}

Twenty-two ewes (Rambouillet, Dorset and crossbreds involving these breeds) were used. Only ewes with previous oestrous cycle lengths of 17 days were used because we have observed that the timing of events related to luteolysis varies for ewes with different cycle lengths and that the length of the oestrous cycle for a particular ewe is constant from cycle to cycle (Zarco et al., 1988). All animals were teased with vasectomized rams twice a day throughout the experimental protocol. Twelve of the ewes were mated with an intact ram when oestrus was first detected (Day 0 ) and were mated again at 12 -h intervals until no longer in oestrus. The remaining 10 animals were left unmated. Jugular blood samples were obtained from all the animals at 2-h intervals from Day 12 to Day 17 after oestrus; the basis for the sampling schedule has been previously presented (Zarco et al., 1988). Plasma was obtained by immediate centrifugation of blood, divided into three aliquots and maintained at $-20^{\circ} \mathrm{C}$ until assayed. The animals that had not been detected in oestrus by Day 19 continued to be checked for oestrus once a day for 10 days. Pregnancy from mating at the designated oestrus was subsequently confirmed by lambing dates.

\section{Hormonal assays}

All samples were analysed for progesterone, 15-keto-13,14-dihydro-PGF-2 $\alpha$, and 11-ketotetranor-PGF metabolites. The analysis of progesterone was done by enzyme immunoassay (Munro \& Stabenfeldt, 1984). The sensitivity of the assay is $75 \mathrm{pg} / \mathrm{ml}$. Intra-assay and inter-assay coefficients of variation varied from $4.9 \%$ to $10.5 \%$ and from $10.9 \%$ to $14.5 \%$, respectively.

The assay for the initial main plasma metabolite of PGF-2 $\alpha, 15-$ keto-13,14-dihydro-PGF-2 $\alpha$, has been previously described (Granström \& Kindahl, 1982a). The sensitivity of the assay is $10 \mathrm{pg} / \mathrm{ml}$, the inter-assay coefficient of variation is $14 \%$, and the intra-assay coefficient of variation ranged from 6.6 to $11.7 \%$. The assay for 11 -ketotetranorPGF metabolites was done according to Granström \& Kindahl (1982b). The sensitivity of the assay is $4 \mathrm{pg}$ and the intra- and inter-coefficients of variation are 6-10\% and 12\%, respectively (Granström \& Kindahl, 1976; Basu et al., 1987). The antibody does not differentiate between the different 11-ketotetranor-PGF compounds. 


\section{Definitions}

Significant pulses of each metabolite were identified in individual animals using an iterative method previously described (Zarco et al., 1984). A significant pulse of PGF-2 $\alpha$ was considered to have occurred when a pulse of one or both of the PGF-2 $\alpha$ metabolites was identified. A pulse consisted of all the consecutive values that were significantly higher than the baseline. Interpulse intervals were determined by the time elapsed between peak values of two consecutive pulses.

Daily mean concentrations of PGF-2 $\alpha$ metabolites were defined as the average value for all the samples taken for a particular day of cycle-pregnancy status combination. Functional luteolysis was considered to have begun at a certain sampling time if the mean progesterone value of the 4 subsequent samples was less than the mean minus 2 standard deviations of all previous samples for that particular ewe. Luteolysis was considered to be complete when progesterone concentrations declined to less than $0.25 \mathrm{ng} / \mathrm{ml}$.

\section{Statistical analysis}

Daily basal concentrations were calculated by eliminating the values identified as pulses, and averaging the remaining values for each day-status combination. Daily mean and basal concentrations of PGF-2 $\alpha$ metabolites were analysed by two-way analysis of variance (ANOVA) using pregnancy status and day after oestrus as independent variables. Multiple comparisons between group means were carried out by the Bonferroni method (Neter \& Wasserman, 1974) when a significant interaction was detected between day after oestrus and pregnancy status. The numbers of samples associated with PGF-2 $\alpha$ pulses were compared to the total number of samples for a particular group. Differences between groups were analysed by $\chi^{2}$ tests. Interpulse intervals were analysed by ANOVA.

\section{Results}

Two of the mated animals returned to oestrus within 18 days from the day of insemination and were eliminated from the study. The lambing dates of the remaining 10 mated animals confirmed that they had conceived and were pregnant during this study. All 10 unmated animals returned to oestrus at the expected time (Day 16.7 \pm 0.1 after oestrus; mean \pm s.e.m.). Luteolysis in these animals was initiated on Day 14.7 \pm 0.3 and was completed on Day $15.6 \pm 0.2$ after oestrus.

The hormonal profiles for one non-pregnant ewe and for 4 pregnant ewes are presented in Figs 1 and 2, respectively. Non-pregnant ewes had pulsatile patterns of PGF-2 $\alpha$ release extending from Days 13 to 16 . In contrast, the pulsatile pattern was greatly modified or absent in pregnant ewes. The number of PGF-2 $\alpha$ pulses was significantly greater in non-pregnant than in pregnant ewes on Days 14,15 and $16(P<0.05)$, and tended to be greater in non-pregnant than in pregnant ewes on Days 12, 13 and 17 (Table 1). The total number of pulses per ewe was greater in non-pregnant than in pregnant ewes $(P<0.05)$. There was great variability in the number of PGF-2 $\alpha$ pulses in pregnant ewes, with 3 pregnant ewes having 8,5 and 4 pulses, while the remaining 7 ewes had $0(1$ ewe), 1 (4 ewes) or 2 ( 2 ewes) pulses.

The mean interpulse interval for non-pregnant ewes and for those pregnant ewes in which more than one pulse was detected ( 5 of 10 pregnant ewes) is shown in Table 2 . The interval between PGF-2 $\alpha$ pulses was shorter for non-pregnant than for pregnant ewes $(P<0.05)$. The pulses of nonpregnant ewes were further classified into pulses occurring before the onset of functional luteolysis and pulses temporally associated with functional luteolysis. These results (Table 2) indicate that luteolysis was preceded by low frequency pulses while the pulses temporally associated with luteolysis were increased in number and frequency.

The daily mean concentrations of 15-keto-13,14-dihydro-PGF-2 $\alpha$ in non-pregnant ewes increased from Day 13 to Day 15 and then decreased; values at Day 15 were significantly higher than at other days $(P<0.05)$ (Fig. 3). When pulse values were eliminated in non-pregnant ewes, the resulting basal concentrations remained below $40 \mathrm{pg} / \mathrm{ml}$. The mean concentrations of 15-keto13,14-dihydro-PGF-2 $\alpha$ in pregnant ewes increased gradually from Day 12 to Day 14 and then decreased gradually from Day 14 to 17; values were significantly higher on Day 14 than on Days 12, 16 and $17(P<0.05)$. The basal concentrations in pregnant ewes were similar to the mean concentrations at all times. 

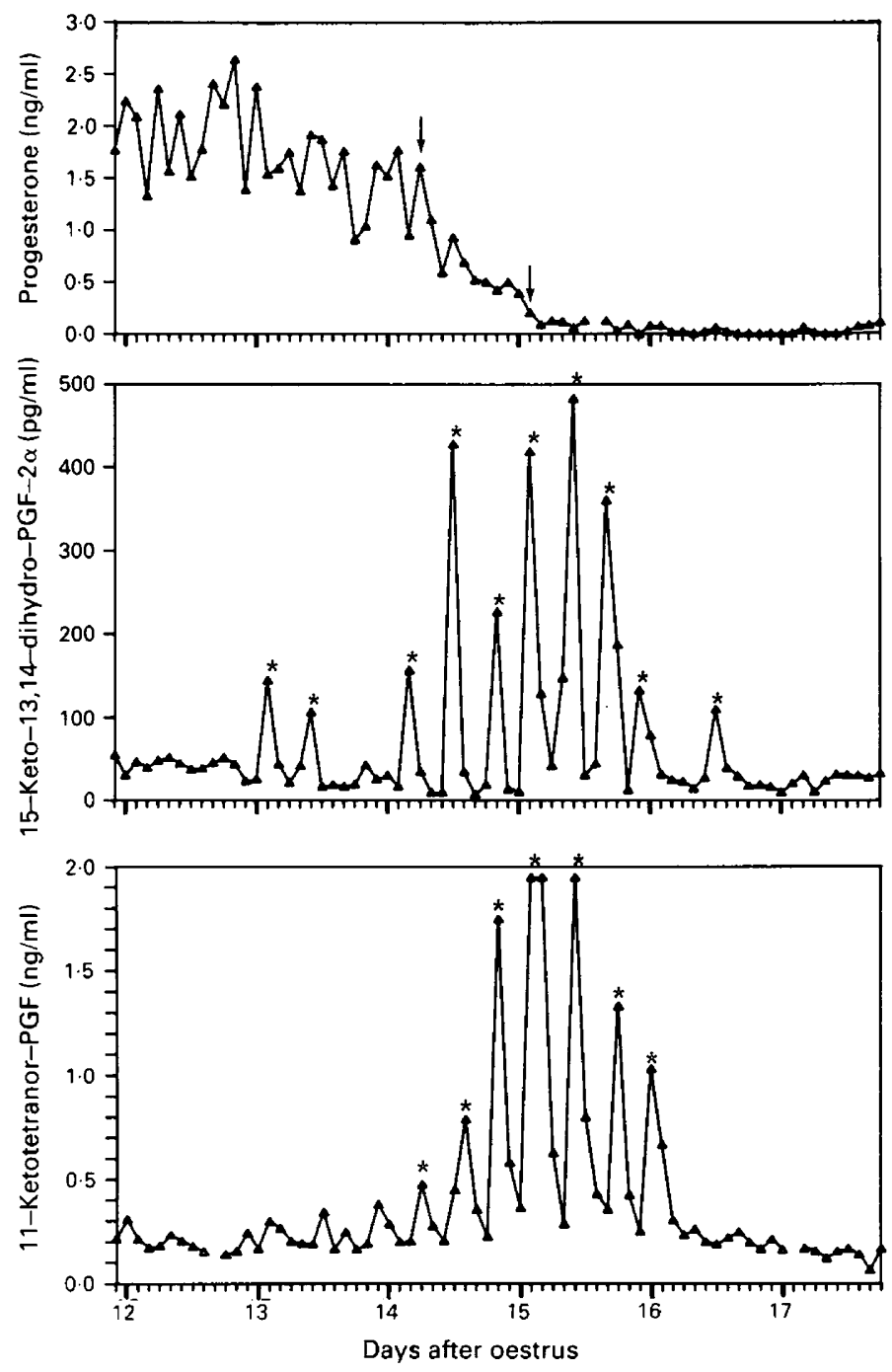

Fig. 1. Concentrations of progesterone, 15-keto-13,14-dihydro-PGF-2 $\alpha$ and 11-ketotetranorPGF metabolites in a non-pregnant ewe. Values identified as significant pulses of either PGF$2 \alpha$ metabolite are indicated by an asterisk. The times of initiation and completion of functional luteolysis are indicated by arrows.

The mean concentrations of 15-keto-13,14-dihydro-PGF-2 $\alpha$ were higher in pregnant than in non-pregnant ewes on Days 13 and 14, and higher in non-pregnant than pregnant ewes on Day 15 $(P<0.05)$ with no significant difference between the two groups at other times. The basal concentrations were higher in pregnant than non-pregnant ewes at Days 13,14,15, 16 and 17 $(P<0.05)$.

The mean and basal concentrations of 11-ketotetranor-PGF metabolites (Fig. 4) followed the same patterns as those of 15-keto-13,14-dihydro-PGF-2 $\alpha$ for the pregnant and non-pregnant ewes. The mean concentrations of 11-ketotetranor-PGF were higher in pregnant than non-pregnant ewes on Day 14 after oestrus and higher in non-pregnant than pregnant ewes on Day $15(P<0.05)$. The basal concentrations were higher in pregnant than non-pregnant ewes on Day $14(P<0.05)$ and similar at other times in pregnant and non-pregnant ewes. 

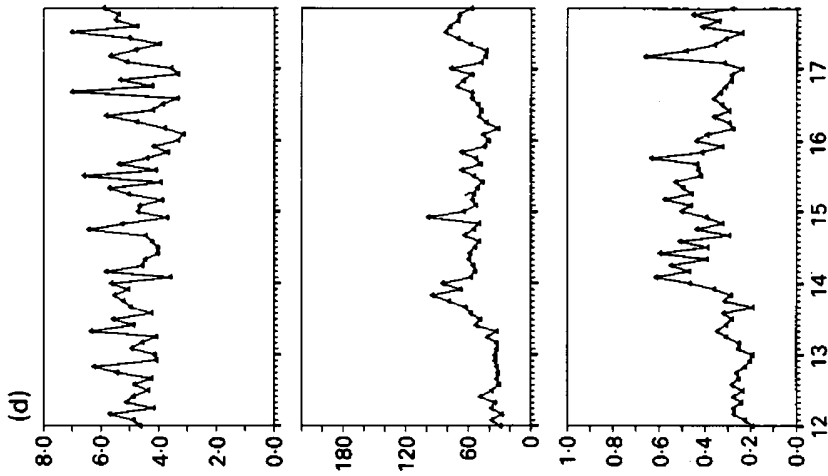

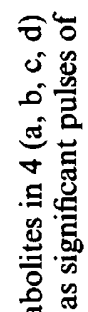
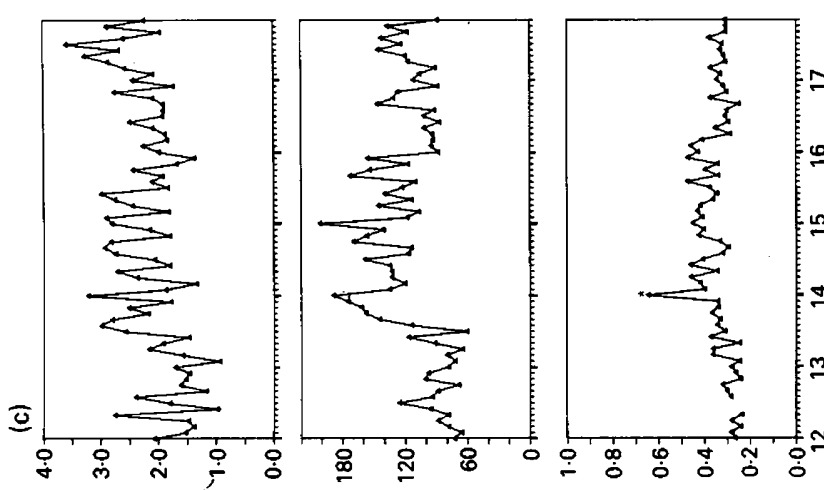

要
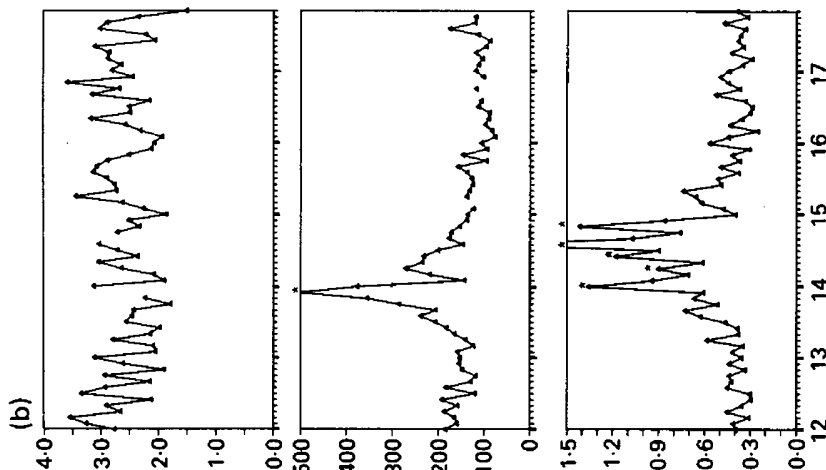

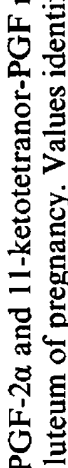

$\sum_{\pi}^{\infty}$

은 을

至

to

m $\frac{1}{0}$

$\div$ 일

을 웜

혼

금잉

氙 焉

농

号

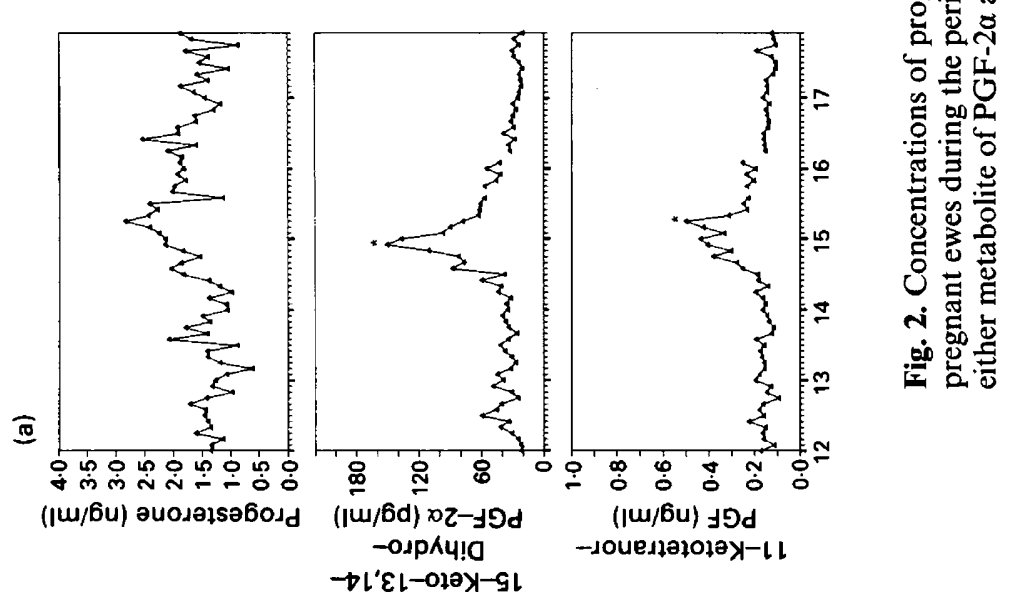


Table 1. Numbers of pulses of PGF-2 $\alpha$ secretion per ewe on different days after oestrus in nonpregnant and pregnant ewes

\begin{tabular}{|c|c|c|}
\hline \multirow[b]{2}{*}{ Day } & \multicolumn{2}{|c|}{ No. of pulses/ewe } \\
\hline & Non-pregnant & Pregnant \\
\hline 12 & $0.2 \pm 0.1 \quad(2 / 112)$ & $0.0 \pm 0.0 \quad(0 / 110)$ \\
\hline 13 & $0.9 \pm 0.2 \quad(9 / 110)$ & $0.3 \pm 0.2 \quad(3 / 118)$ \\
\hline $14^{*}$ & $2 \cdot 0 \pm 0.3(20 / 120)$ & $0.9 \pm 0.3 \quad(9 / 117)$ \\
\hline $15^{*}$ & $3.3 \pm 0.2(33 / 120)$ & $0.8 \pm 0.2 \quad(8 / 119)$ \\
\hline $16^{*}$ & $1.5 \pm 0.3(15 / 116)$ & $0.3 \pm 0.2 \quad(3 / 115)$ \\
\hline 17 & $0.3 \pm 0.1 \quad(3 / 111)$ & $0.1 \pm 0.1 \quad(1 / 118)$ \\
\hline Total* & $8 \cdot 2 \pm 0 \cdot 4(80 / 689)$ & $2.5 \pm 0.7(25 / 697)$ \\
\hline
\end{tabular}

Values are mean \pm s.e.m. for 10 ewes/group.

Values in parentheses are total no. of puises/total no. of samples and are the values used for the $\chi^{2}$ test.

*Values for pregnant and non-pregnant ewes are different $(P<0.05)$.

Table 2. Number of PGF-2 $\alpha$ pulses and interval between pulses in non-pregnant and pregnant ewes

\begin{tabular}{|c|c|c|}
\hline Group & $\begin{array}{c}\text { No. of } \\
\text { pulses/ewe } \dagger\end{array}$ & $\begin{array}{c}\text { Interval } \\
\text { between } \\
\text { pulses }(h)_{+}^{\ddagger}\end{array}$ \\
\hline Non-pregnant & $8 \cdot 2 \pm 0 \cdot 4^{*}$ & $\frac{10 \cdot 7 \pm 0 \cdot 7^{*}}{(72)}$ \\
\hline $\begin{array}{l}\text { Pulses before start } \\
\text { of luteolysis }\end{array}$ & $2 \cdot 2 \pm 0 \cdot 3$ & $13 \cdot 4 \pm \frac{1}{(22)} \cdot 6$ \\
\hline $\begin{array}{l}\text { Pulses coincidental } \\
\text { with luteolysis }\end{array}$ & $6 \cdot 0 \pm 0 \cdot 3^{*}$ & $\begin{array}{c}7 \cdot 9 \pm 0 \cdot 4^{*} \\
(46)\end{array}$ \\
\hline Pregnant & $2 \cdot 5 \pm 0.7$ & $\begin{array}{c}18 \cdot 9 \pm 6 \cdot 1 \\
(18)\end{array}$ \\
\hline
\end{tabular}

\section{Discussion}

Our results agree with those who have reported a pulsatile release of PGF- $2 \alpha$ in non-pregnant animals and the absence of this pulsatile pattern of PGF- $2 \alpha$ secretion in pregnant animals (Thorburn et al., 1972, 1973; Barcikowski et al., 1974; Roberts et al., 1975; Peterson et al., 1976; McCracken, 1980; McCracken et al., 1984; Hooper et al., 1986). Our results also agree with those reporting no difference in mean concentrations of PGF- $2 \alpha$ or its metabolites in pregnant and nonpregnant ewes (Wilson et al., 1972; Pexton et al., 1975a, b; Nett et al., 1976; Lewis et al., 1977, 1978; Ellinwood et al., 1979; Silvia et al., 1984). This apparent contradiction can be explained by our 


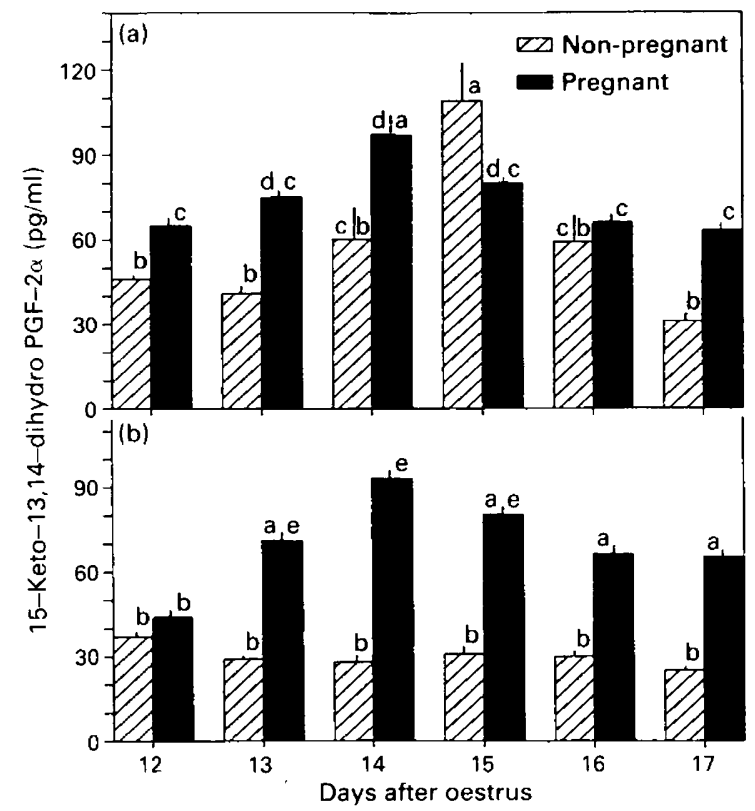

Fig. 3. Mean (a) and basal (b) concentrations of 15-keto-13,14-dihydro-PGF-2 $\alpha$ in nonpregnant and pregnant ewes. Values are represented as mean \pm s.e.m. of 110 observations per group (day $\times$ status combination). Within each panel, bars without at least one common superscript are statistically different $(P<0.05)$. Comparisons of mean and basal concentrations were not done.

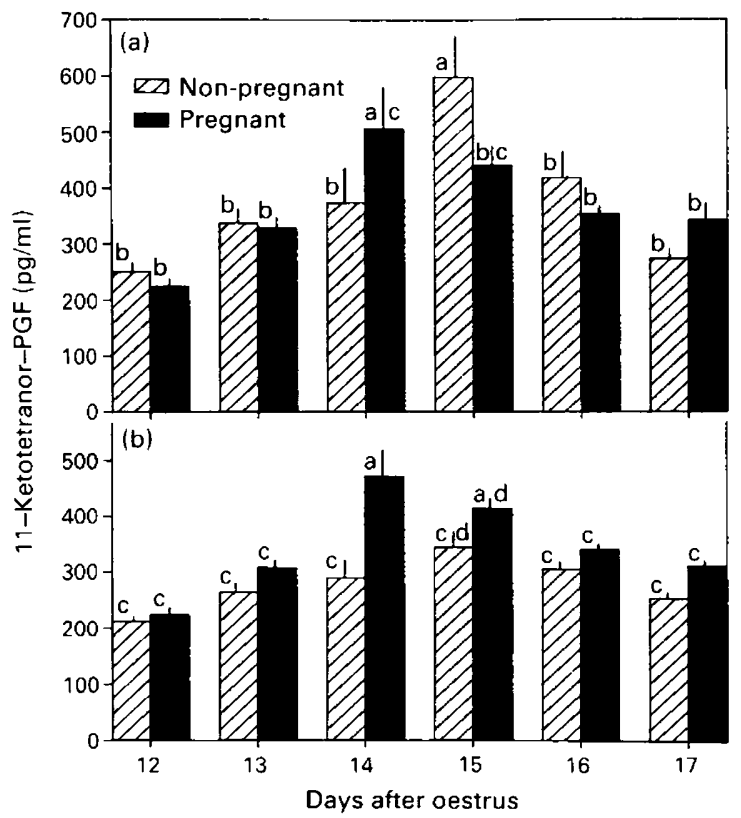

Fig. 4. Mean (a) and basal (b) concentrations of 11-ketotetranor-PGF metabolites in nonpregnant and pregnant ewes. Values are represented as mean \pm s.e.m. of 108 observations per group (day $\times$ status combination). Within each panel, bars without at least one common superscript are statistically different $(P<0.05)$. Comparisons of mean and basal concentrations were not done. 
finding that the basal secretion of PGF- $2 \alpha$ is increased in pregnant as compared with non-pregnant ewes. The increased secretion of PGF- $2 \alpha$ in pregnant animals compensates for the absence of pulses when computing mean concentrations so that the values of mean concentrations are similar in pregnant and non-pregnant ewes even in the presence of different patterns of PGF- $2 \alpha$ release.

Our results demonstrate that the production of PGF- $2 \alpha$ increases in the pregnant and nonpregnant ewes to peak at Days 14-15 after oestrus. However, the patterns of PGF-2 $\alpha$ synthesis and release differ, pregnant ewes being characterized by a changing basal secretion with few or no pulses, while non-pregnant ewes are characterized by the development of a marked pulsatile pattern superimposed on a constant baseline. In fact, true pulses of PGF- $2 \alpha$ synthesis and release as observed during luteolysis in non-pregnant animals were not observed in pregnant ewes. Similar findings were reported previously for the sow (Shille et al., 1979) and goat (Fredriksson et al., 1984). Furthermore, while Lacroix \& Kann (1986) did not find PGF-2 $\alpha$ pulses in pregnant sheep between Days 14 and 20 after oestrus, they found higher concentrations of 15-keto-13,14-dihydroPGF-2 $\alpha$ on Days 14-16 than on Day 17 after oestrus in pregnant ewes. In the pig, goat and sheep, therefore, the gravid uterus is unable to produce PGF- $2 \alpha$ in a pulsatile mode. However, the ability to synthesize and release PGF-2 $\alpha$ is present in non-gravid and gravid uteri, synthesis being in a continuous and increasing mode in pregnant animals at the time of CL rescue (Days 12-14) as compared to a pulsatile mode in non-pregnant animals at the time of demise of the CL.

It is evident that the development of the uterine ability to produce PGF-2 $\alpha$ evolves in parallel in pregnant and non-pregnant ewes since removal of the embryo as late as Day 14 of the cycle results in an almost immediate onset of luteolysis and only slight prolongation of the oestrous cycle (Martal et al., 1979). This has been consistently demonstrated by experiments in which synthesis and release of PGF-2 $\alpha$ by endometrial tissue incubated in vitro has been shown to be similar or greater in tissue from pregnant ewes than in tissue from non-pregnant ewes (Ellinwood et al., 1979; Findlay et al., 1981; Lacroix \& Kann, 1982, 1983). There is also experimental evidence to support our suggestion that the gravid uterus has limited (or no) capacity for pulsatile secretion of PGF- $2 \alpha$ in that McCracken et al. (1981) showed that the early gravid uterus was refractory to intra-arterial challenges of oxytocin in terms of PGF- $2 \alpha$ synthesis and release as compared to the response of the non-gravid uterus. Lacroix \& Kann (1986) showed that the pregnant ewe does not respond with pulses of 15-keto-13,14-dihydro-PGF-2 $\alpha$ as do non-pregnant ewes when treated with oestradiol.

The mechanism by which uterine release of PGF- $2 \alpha$ in a pulsatile manner is suppressed in the pregnant ewe is not known. Oxytocin has been strongly implicated as the acute regulator of individual episodes of PGF-2 $\alpha$ release during luteolysis (Fairclough et al., 1980; Flint \& Sheldrick, 1983; McCracken et al., 1984). McCracken et al. (1981) reported that the number of oxytocin receptors in endometria obtained from early pregnant ewes was one tenth that found in endometria from non-pregnant ewes and, as mentioned previously, the gravid uterus is unable to respond to oxytocin infusion with release of PGF- $2 \alpha$. It has been proposed that the embryo could prevent the pulsatile release of PGF-2 $\alpha$ by suppressing the synthesis of oxytocin receptors in the endometrium (McCracken et al., 1984). This lack of receptors might in turn be due to the reduced sensitivity of the endometrium to oestrogens reported by Lacroix \& Kann (1986), since the synthesis of oxytocin receptors is oestrogen-dependent (McCracken, 1980).

From our finding that the basal release of PGF-2 $\alpha$ is continuously increased in pregnant ewes as compared to non-pregnant ewes starting on Day 12 after oestrus, one speculation is that the luteoprotective effect of the embryo could be due, in part, to continued increased secretion of PGF- $2 \alpha$ by the gravid uterus. McCracken et al. (1984) found that more PGF-2 $\alpha$ is required to cause complete luteolysis when administered as a continuous infusion rather than as a series of pulses.

Due to the high rate of embryonic mortality during the first 2 weeks of pregnancy in the ewe (Moore \& Rowson, 1960; Quinlivan et al., 1966), the ability of the embryo to permit the gradual development of the uterine capacity to produce PGF- $2 \alpha$ and yet be able to prevent luteolysis effectively by inhibition of the pulsatile release of this hormone, represents an evolutionary advantage. It allows for a parallel development of the uterine PGF-2 $\alpha$ synthetic ability in pregnant and 
non-pregnant ewes up to Day 12 or 13 after oestrus. At that time, when much of the risk of embryonic death has passed, an assessment of the presence of an embryo results in maintenance of the corpus lutuem by blockade of the pulsatile release of PGF-2 $\alpha$ in spite of the uterine ability to produce the hormone. On the other hand, embryonic death occurring as late as Day 13 or 14 after oestrus, can still result in immediate regression of the CL because the enzyme systems for PGF-2 $\alpha$ production have already been developed.

In contrast, if maternal recognition of pregnancy were the result of suppression of the development of the PGF- $2 \alpha$ synthesizing system, the decision between pregnant and non-pregnant status would have to be made very early in the cycle, i.e. when enzyme systems begin to develop. In this situation, an animal losing an embryo on Day 11 after oestrus would have a cycle length of about 25 days instead of the 16-17-day cycle length that actually occurs when an embryo is removed as late as Day 14 (Martal et al., 1979). This would result in a waste of reproductive potential in ewes that experienced early embryonic death when they were already committed to pregnancy.

It is concluded that the embryo prevents luteolysis by suppressing the ability of the uterus to release PGF-2 $\alpha$ in a pulsatile fashion without reducing the ability of the uterus to synthesize the hormone. This mechanism makes it possible for a late commitment to be made for the onset of normal luteolysis in the event of embryonic death.

We thank Coralie Munro for technical help. Supported in part by the California Agricultural Experiment Station, Hatch project "Manipulation of Postpartum Period in Ruminants" and by the Swedish Council for Forestry and Agricultural Research. L.Z. was supported by a fellowship of the Organization of American States.

\section{References}

Barcikowski, B., Carlson, J.C., Wilson, L. \& McCracken, J.A. (1974) The effect of endogenous and exogenous estradiol-17 $\beta$ on the release of prostaglandin F-2 $\alpha$ from the ovine uterus. Endocrinology 95, 1340-1349.

Basu, S., Kindahl, H., Harvey, D. \& Betteridge, K.J. (1987) Metabolites of PGF-2 $\alpha$ in blood plasma and urine as parameters of PGF-2 $\alpha$ release in cattle. Acta vet. scand., in press.

Ellinwood, W.E., Nett, T.M. \& Niswender, G.D. (1979) Maintenance of the corpus luteum of early pregnancy in the ewe. II. Prostaglandin secretion by the endometrium in vitro and in vivo. Biol. Reprod. 21, 845-856.

Fairclough, R.J., Moore, L.G., McGowan, L.T., Peterson, A.J., Smith, J.F., Tervit, H.R. \& Watkins, W.B. (1980) Temporal relationship between plasma concentrations of 13,14-dihydro-15-keto-prostaglan$\operatorname{din} \mathrm{F}$ and neurophysin $\mathrm{I} / \mathrm{II}$ around luteolysis in sheep. Prostaglandins 20, 199-208.

Findlay, J.K., Ackland, N., Burton, R.D., Davis, A.J., Maule Walker, F.M., Walters, D.E. \& Heap, R.B. (1981) Protein, prostaglandin and steroid synthesis in caruncular and intercaruncular endometrium of sheep before implantation. J. Reprod. Fert. 62, $361-377$.

Flint, A.P.F. \& Sheldrick, E.L. (1983) Evidence for a systemic role for ovarian oxytocin in luteal regression in sheep. J. Reprod. Fert. 67, 215-225.

Fredriksson, G., Kindahl, H. \& Edqvist, L.-E. (1984) 11 Ketotetranor-PGF metabolites, a. suitable indicator for measuring prostaglandin release during the normal oestrous cycle and early pregnancy in the goat. Anim. Reprod. Sci. 7, 537-545.

Granström, E. \& Kindahl, H. (1976) Radioimmunoassay for urinary metabolites for prostaglandin $F-2 \alpha$. Prostaglandins 12, 759-783.

Granström, E. \& Kindahl, H. (1982a) Radioimmunoassay of the major plasma metabolite of PGF-2 $\alpha$, 15-keto-13,14,dihydro-PGF-2 $\alpha$. Methods Enzymol. 86, 320-339.

Granström, E. \& Kindahl, H. (1982b) Radioimmunoassay of 5,7a-dihydroxy-11-ketotetranorprostane1,16-dioic acid, a major prostaglandin F metabolite in blood and urine. Methods Enzymol. 86, 339-353.

Hooper, S.B., Walker, D.W. \& Thorburn, G.D. (1986) Cannulation of the utero-ovarian vein in intact ewes: Hormone concentrations and blood gas levels during the oestrous cycle and pregnancy. Acta endocr., Copenh. 112, 253-262.

Lacroix, M.C. \& Kann, G. (1982) Comparative studies of prostaglandins $\mathrm{F}-2 \alpha$ and $\mathrm{E} 2$ in late cyclic and early pregnant sheep: in vitro synthesis by endometrium and conceptus effects of in vivo indomethacin treatment on establishment of pregnancy. Prostaglandins 23, 507-526.

Lacroix, M.C. \& Kann, G. (1983) Discriminating analysis of "in vitro" prostaglandin release by myometrial and luminal sides of the ewe endometrium. Prostaglandins 25, 853-869.

Lacroix, M.C. \& Kann, G. (1986) Aspects of the antiluteolytic activity of the conceptus during early pregnancy in ewes. J. Anim. Sci. 63, 1449-1458. 
Lewis, G.S., Wilson, L., Wilks, J.W., Pexton, J.E., Fogwell, R.L., Ford, S.P., Butcher, R.L., Thayne, W.V. \& Inskeep, E.K. (1977) PGF-2 $\alpha$ and its metabolites in uterine and jugular venous plasma and endometrium of ewes during early pregnancy. $J$. Anim. Sci. 45, 320-327.

Lewis, G.S., Jenkins, P.E., Fogwell, R.L. \& Inskeep, E.K. (1978) Concentrations of prostaglandins E2 and F-2 $\alpha$ and their relationship to luteal function in early pregnant ewes. J. Anim. Sci. 47, 1314-1323.

Martal, J., Lacroix, M.-C., Loudes, C., Saunier, M. \& Winterberger-Torres, S. (1979) Trophoblastin, an antiluteolytic protein present in early pregnancy in sheep. J. Reprod. Fert. 56, 63-73.

McCracken, J.A. (1980) Hormone receptor control of prostaglandin F-2 $\alpha$ secretion by the ovine uterus. Adv. Prostaglandin Thromboxane Res. 8, 1329-1344.

McCracken, J.A., Schramm, W., Barcikowski, B. \& Wilson, L., Jr (1981) The identification of prostaglandin F-2 $\alpha$ as a uterine luteolytic hormone and the hormonal control of its synthesis. Acta vet. scand. Suppl. 77, 71-88.

McCracken, J.A., Schramm, W. \& Okulicz, W.C. (1984) Hormone receptor control of pulsatile secretion of PGF-2 $\alpha$ from the ovine uterus during luteolysis and its abrogation in early pregnancy. Anim. Reprod. Sci. 7, 31-55.

Moore, N.W. \& Rowson, L.E.A. (1960) Egg transfer in sheep. Factors affecting the survival and development of transferred eggs. J. Reprod. Fert. 1, 332-349.

Munro, C. \& Stabenfeldt, G. (1984) Development of a microtitre plate enzyme immunoassay for the determination of progesterone. J. Endocr. 101, 41-49.

Neter, J. \& Wasserman, W. (1974) Applied Linear Statistical Models, pp.419-635. Irwin-Dorsey Ltd, Homewood, IL.

Nett, T.M., Staigmiller, R.B., Akbar, A.M., Diekman, N.A., Ellinwood, W.E. \& Niswender, G.D. (1976) Secretion of prostaglandin $\mathrm{F}-2 \alpha$ in cycling and pregnant ewes. J. Anim. Sci. 42, 876880 .

Peterson, A.J., Tervit, H.R., Fairclough, R.J., Havik, P.G. \& Smith, J.F. (1976) Jugular levels of 13,14dihydro-15-keto-prostaglandin $F$ and progesterone around luteolysis and early pregnancy in the ewe. Prostaglandins 12, 551-558.

Pexton, J.E., Weems, C.W. \& Inskeep, E.K. (1975a) Prostaglandins $\mathrm{F}$ in uterine venous plasma, ovarian arterial and venous plasma and in ovarian and luteal tissue of pregnant and nonpregnant ewes. J. Anim. Sci. 41, $154-159$.

Pexton, J.E., Weems, C.W. \& Inskeep, E.K. (1975b) Prostaglandins $F$ in uterine and ovarian venous plasma from nonpregnant and pregnant ewes collected by cannulation. Prostaglandins 9, 501-509.

Quinlivan, T.D., Martin, C.A., Taylor, W.B. \& Cairney, I.M. (1966) Estimates of pre- and perinatal mortality in the New Zealand Romney Marsh ewe. J. Reprod. Fert. 11, 379-390.

Roberts, J.S., Barcikowski, B., Wilson, L., Skarnes, R.C. \& McCracken, J.A. (1975) Hormonal and related factors affecting the release of prostaglandin $F-2 \alpha$ from the uterus. J. Steroid Biochem. 6, 1091-1097.

Shille, V.M., Karlbom, I., Einarsson, S., Larsson, K., Kindahl, H. \& Edqvist, L.-E. (1979) Concentrations of progesterone and 15-keto-13,14-dihydroprostaglandin $F-2 \alpha$ in peripheral plasma during the estrous cycle and early pregnancy in gilts. Zentbl. VetMed. A 26, 169-181.

Silvia, W.J., Ottobre, J.S. \& Inskeep, E.K. (1984) Concentrations of prostaglandins E2, F-2 $\alpha$ and 6-ketoprostaglandin $\mathrm{Fl}$ in the utero-ovarian venous plasma of nonpregnant and early pregnant ewes. Biol. Reprod. 30, 936-944.

Thorburn, G.D., Cox, R.I., Currie, W.B., Restall, B.J. \& Schneider, W. (1972) Prostaglandin F concentration in the utero-ovarian venous plasma of the ewe during the oestrous cycle. J. Endocr. 53, 325-326.

Thorburn, G.D., Cox, R.I., Currie, W.B., Restall, B.J. \& Schneider, W. (1973) Prostaglandin F and progesterone concentrations in the utero-ovarian venous plasma of the ewe during the oestrous cycle and early pregnancy. J. Reprod. Fert., Suppl. 18, 151-158.

Wilson, L., Butcher, R.L. \& Inskeep, E.K. (1972) Prostaglandin $F-2 \alpha$ in the uterus of ewes during early pregnancy. Prostaglandins 1, 479-481.

Zarco, L., Stabenfeldt, G.H., Kindahl, H., Quirke, J.F. \& Granström, E. (1984) Persistence of luteal activity in the non-pregnant ewe. Anim. Reprod. Sci. 7, 245 267.

Zarco, L., Stabenfeldt, G.H., Quirke, J.F., Kindahl, H. \& Bradford, G.E. (1988) Release of prostaglandin F-2 $\alpha$ and the timing of events associated with luteolysis in ewes with oestrous cycles of different lengths. $J$. Reprod. Fert. 83, 517-526.

Received 23 July 1987 